\title{
Spatio Temporal Land Use Land Cover Change Mapping of Malete Elemere: Implication on Development Planning of Emerging Communities
}

\author{
Henry Sawyerr ${ }^{1}$, Gabriel Salako ${ }^{1}$, Oluwasogo Olalubi ${ }^{5}$, Abdulrasheed Adio $^{3}$, Abel \\ Adebayo $^{2}$, Biola Badmos ${ }^{1}$, Umar Mohd $\mathrm{Jambo}^{4}$, Grace Adepoju ${ }^{3}$
}

\author{
${ }^{1}$ Department of Environmental Management and Toxicology Kwara State University Malete Nigeria \\ ${ }^{2}$ Department of Geography Modibbo Adama University of Technology Yola Nigeria \\ ${ }^{3}$ Department of Plant and Environmental Biology Kwara State University Malete Nigeria \\ ${ }^{4}$ Department of Geography Umar Suleiman College of Education Gashua Yobe Nigeria \\ ${ }^{5}$ Department of Public health Kwara State University Malete Nigeria
}

\begin{abstract}
The use of Ecosystem and Biodiversity mapping, land use land cover change detection has been advocated in preparation of developmental master plan in towns and cities. Noticeable changes have been observed within Malete Elemere community since the establishment of Kwara State University Malete, yet its spatial pattern and socio ecological implication have not been investigated. This work seek to determine and produce land cover land use change map of Malete Elemere over the last 10 years and post 15 year periods through change detection techniques so as to evaluate the impact of the establishment of Kwara State university on the settlement spatial development. Landsat 7 Enhanced Thematic Mapper Plus (ETM+) satellite images of 2005, 2010 and 2015 of the study area were acquired from USGS at spatial resolution of $30 \mathrm{~m}$. Radiometric correction were applied to all the images using radiance modules in Idrisi32 with radiance spectral value set at DN 0 (Lmin) and 255 (Lmax). An unsupervised classification was carried out on the composite images of bands 4,3,2,1 for all the selected years to identify possible maximum spectral reflectance classes, this was followed by supervised classification using training sample from the field survey from which image to image spatio-temporal changes statistics were extracted. To generate a prediction of LULC changes for 2025, Cellular Automata-Markovian transition estimator (CA-Markov) in Idrisi32 was used. Various Kappa statistics was used to evaluate the performance of prediction with an average $K$ statistics of above 0.83 recorded. The result shows that built up area gained an astronomical increase (180\%) between 2005 and 2015 while forest lost significantly $(34 \%)$ within the same periods, with most of the gains occurring in 2010 and 2015 after the establishment of
\end{abstract}

KWASU. By 2025, two Major growth pole centres will emerge along Malete Elemere Axis and one minor in Jenkunu Omoni Axis which will exert a great stress on infrastructural facilities and may create a chaotic condition if left unattended to.

Keywords- Land use land cover (LULC) change, Spatio temporal, prediction, developmental planning.

\section{INTRODUCTION AND LITERATURE REVIEW}

Ecosystem and Biodiversity Mapping (EBM) has been a veritable tool being used by environmental managers and scientists for sustainable land use and planning of natural resources (Fuller et al 2014, Barthlothet al., 1999). EBM does not only provide information on spatial distribution of species across the landscape but also serve as vital source of information on species natural habitat, species values and functions, the level and magnitude of any disturbance in the ecosystem (land cover land use change) all of which have great implication on developmental planning (Hegazy and Kaloop, 2015). Given the rate of deforestation and loss of biodiversity especially in developing countries through carelessness, poor planning and high level of poverty which has put undue pressure on natural resources, it is practically challenging to attain sustainable development without adequate information on the ecosystem and the biotic and abiotic composition (Gladstone and Thomas, 1990). The use of ecosystem land use land cover change detection and biodiversity mapping have been advocated in preparation of developmental master plan in towns and cities. This could help development planners in identifying protected areas, open space and designing of zoning (BRC, 2013). The Biodiversity Resources Centre, New York United States 
had undertaken the habitat (biodiversity) mapping project for over ten towns in Hudsonia developed areas as a tool for town and country planning.

Geographical Information System and Remote Sensing (GIS/RS) have proven to be very useful for large scale mapping of ecosystem and land cover (Trisuratet al., 2000; Foody 2002; Lu and Weng, 2007). These approaches are faster and enable wider geographic coverage within limited time frame (USGS/GAP, 2002; Lowry et al., 2005). Many studies on land cover and vegetation/ecosystem mapping have used data from Advanced Very High Resolution Radiometer AVHRR (Defries and Townsend, 2002), Multispectral Moderate Resolution Imaging Spectra Radiometer-MODIS (Xiao et al., 2002), and Landsat Enhanced Thematic Mapper PlusETM+ (Lu and Weng, 2007; Yuan et al., 2006; Yang and Lo, 2002). While, AVHRR was originally designed for meteorological service and has only two spectral bandsred and near infrared which although sufficient for basic vegetation study, MODIS though has low spatial resolution yet has more spectral bands including short wave infrared (SWIR) which can be used for obtaining greater details and advanced vegetation analysis such as leaf moisture, soil moisture, canopy water contents among others (Boleset al., 2006;Caccetoet al., 2002a, b)
Malete and its adjoining settlements were and still are rural communities with the establishment of Kwara State University Malete (KWASU) campus in 2009. It has since witnessed significant physical infrastructural development many of which are done with little or no consideration for its ecological implication, now that the development is still at its early stage and given the vision of KWASU to prepare a Development Master Plan.

\subsection{Aim}

To assess the landscape dynamics prior and since the establishment of KWASU and predict the socio economic and ecological implication on the adjoining community.

\subsubsection{Objectives:}

- To assess the landscape dynamics prior to and since the establishment of KWASU and predict the socio economic and ecological implication on the adjoining community.

- To determine biodiversity loss/gain over 15 year periods through change detection techniques and highlight its implication on developmental Planning.

- To predict possible land use pattern in the next 15 years and the relevant planning strategies to adopt.

\section{MATERIALS AND METHOD}

\subsection{Study Area}

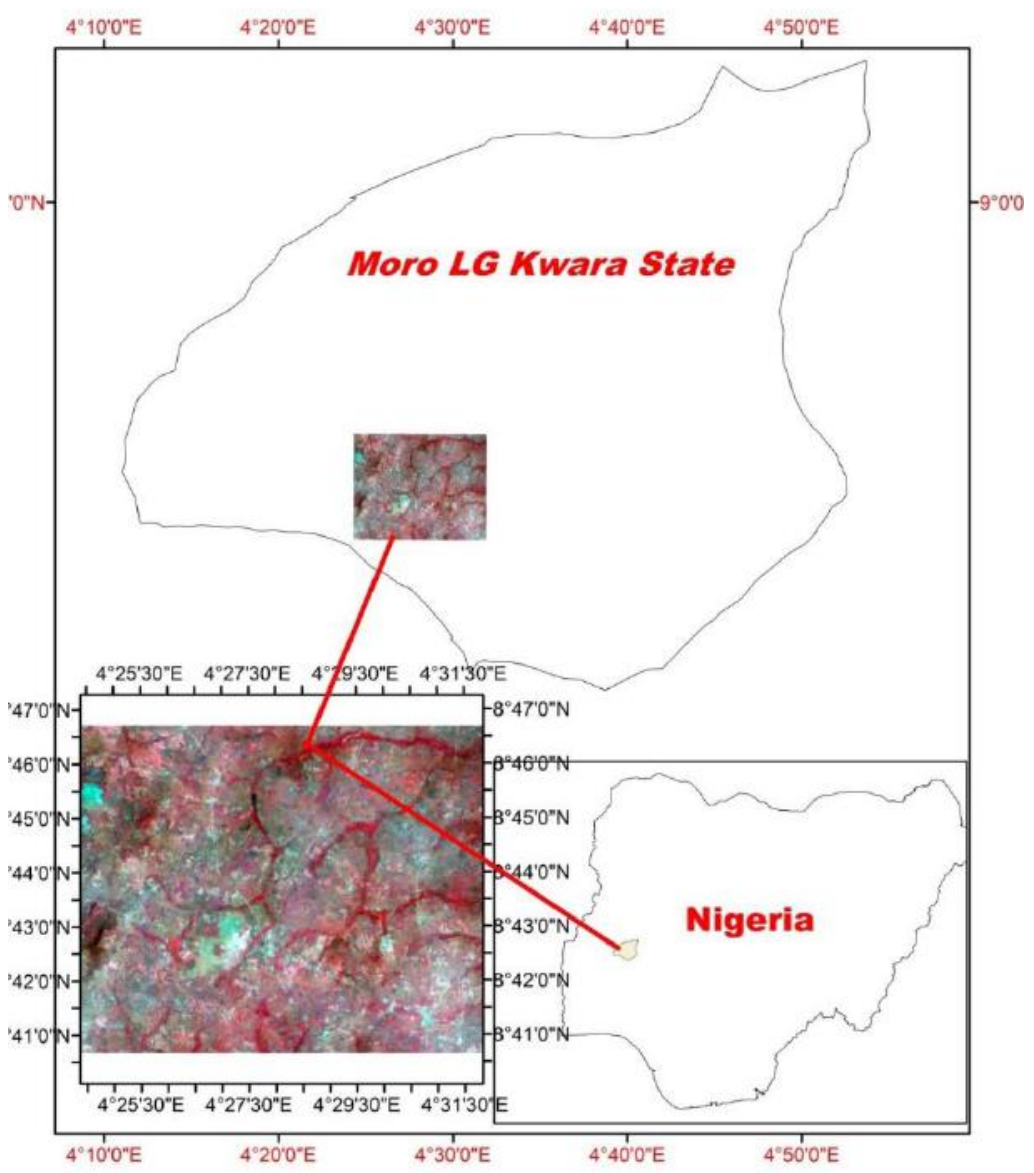

Fig.1: The study area with Nigeria map inset 
The study area is located in Moro Local Government Area of Kwara State and lies within latitude $8.6563^{\circ} \mathrm{N}$ to $8.8136^{\circ} \mathrm{N}$ and longitudes $4.2359^{\circ} \mathrm{E}$ to $4.5410^{\circ} \mathrm{E}$. It comprises of Malete, Elemere, KWASU Campus, and the adjoining communities covering an area of about $(157,701$ Hectares) of land.
The study area is about $25 \mathrm{~km}$ North of Ilorin, the Kwara State capital though a relatively virgin area, it is highly vulnerable to unplanned expansions due to its proximity to the state capital and recently the siting of KWASU campus.

\subsection{Methodology Flow Chart}

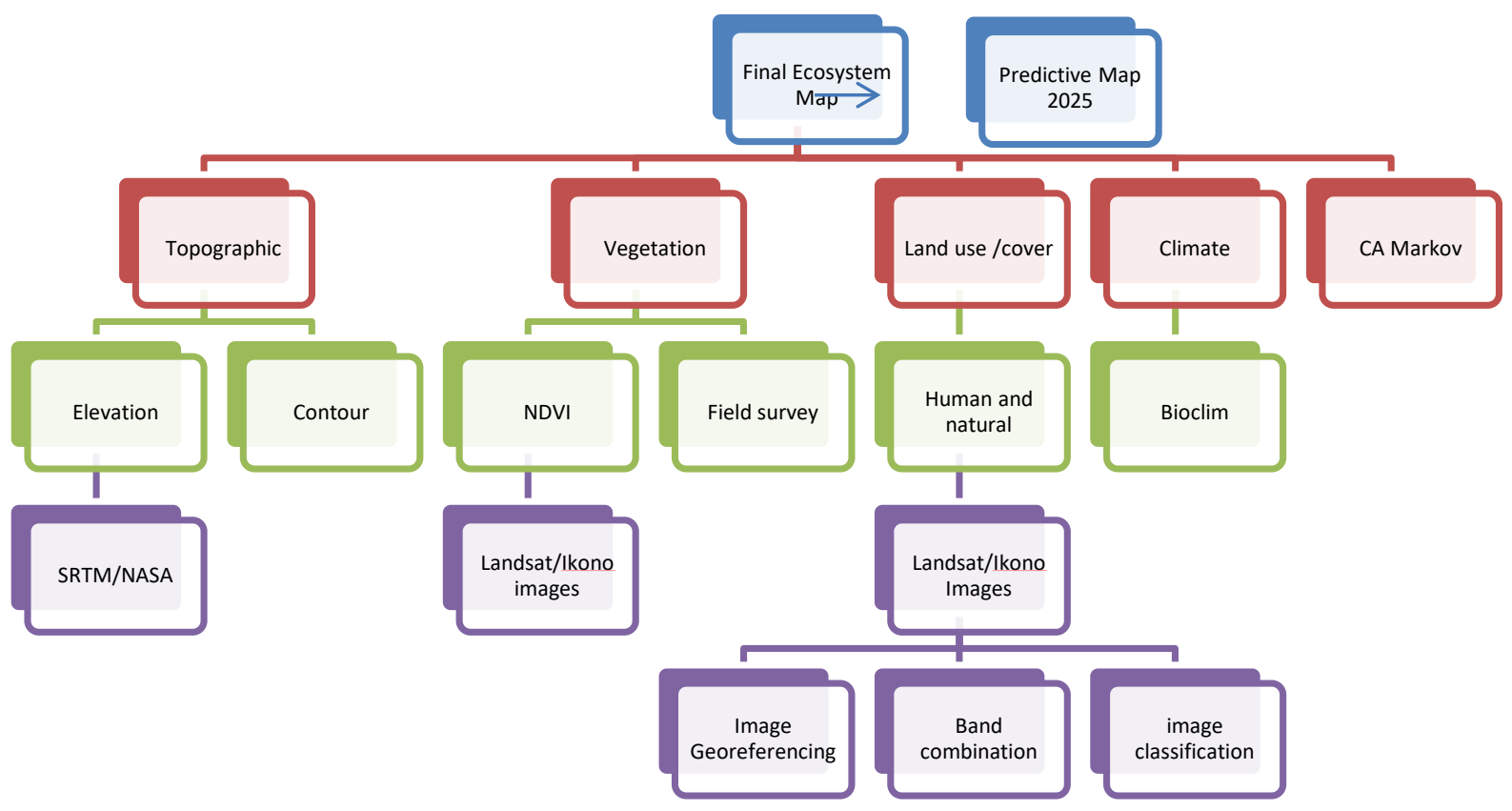

Fig.2: Methodology flow chart

\subsection{Materials}

The geographic extent of the study area was first determined and the shapefile prepared in Arc GIS 10.2. All the satellite images were co registered to the same study area shapefile to give similar spatial dimension.
Archive Landsat 7 Enhanced Thematic Mapper Pus (ETM+) satellite images of 2005, 2010 and 2015 of the study area were acquired from USGS at spatial resolution of $30 \mathrm{~m}$.

Table.1: Summary of data acquired and used

\begin{tabular}{|c|c|c|c|c|c|}
\hline $\mathbf{S} / \mathbf{N}$ & Data Type & $\begin{array}{c}\text { Years of } \\
\text { Acquisition }\end{array}$ & $\begin{array}{l}\text { Resolution / } \\
\text { Scale }\end{array}$ & Source & Application \\
\hline 1 & $\begin{array}{l}\text { Landsat ETM+ } \\
\text { Images }\end{array}$ & $\begin{array}{l}2005,2010 \\
2015\end{array}$ & $30 \mathrm{~m}$ & GLCF/USGS & $\begin{array}{l}\text { Land cover Mapping } \\
\text { (NDVI) }\end{array}$ \\
\hline 2 & $\begin{array}{l}\text { Digital Elevation } \\
\text { Model (DEM) }\end{array}$ & 2000 & $90 \mathrm{~m}$ & SRTM/NASA & Physiographic Mapping \\
\hline 3 & GeoEye-1 & 2016 & $40 \mathrm{~cm}$ & TerraServer & $\begin{array}{l}\text { Image } \\
\text { Validation/Classification }\end{array}$ \\
\hline 4 & Climatic Data & $\begin{array}{c}1900-2000 \\
2000-2013\end{array}$ & $0.86 \mathrm{~km}^{2}$ & $\begin{array}{l}\text { WorldClim / } \\
\text { URBDA }\end{array}$ & Bioclimatic classification \\
\hline 5 & Species Occurrence & 2005 & Nil & $\begin{array}{l}\text { GPS/GBIF } \\
\text { Google Earth } \\
\text { Field work }\end{array}$ & Suitability index \\
\hline 6 & Soil Data & 2007 & $250 \mathrm{~m}$ & UNEP & Physiographic Mapping \\
\hline 7 & Vegetation data & 2013 & $25 \mathrm{~m} \times 4 \mathrm{~m}$ & Field Work & Veg/Classification \\
\hline
\end{tabular}


Global land Cover facility $=\mathbf{~ G L C F}$

Shuttle Radar Topographic Mission $=$ SRTM

Global Biodiversity Information Facility $=$ GBIF

Upper Benue River Basin Development Authority = URBDA

National Aeronautics and Space Administration = NASA

United Nation Environmental Programme = UNEP

\subsection{Image Pre-Processing}

Radiometric corrections were applied to all the images using radiance modules in Idrisi 32 with radiance spectral value set at DN 0 (Lmin) and 255 (Lmax). All images were collected in the months of July respectively being the possible periods of rainy seasons for effective measurement of plant vigour. Attempt was made to collect cloud free images in all the time series. Images band combinations were performed on bands $3,2,1$ and 4, 3, 2 for classification (urban, water bodies and agriculture) and vegetation differencing (forest and grassland) respectively.

\subsection{Image Processing}

The unsupervised classification was carried out on the composite images of bands 4,3,2,1 based on pixel spectral characteristics/signatures of various land cover. An iterative ISODATA (Maximum Likelihood Classifier) algorithm was used in ArcView GIS (version 10.2) and Multispec (2013 version). This grouped similar pixels in the image into clusters or categories, and help us in determining maximum spectral classes in the images. There was no significant class change after eight spectral classes thus provided a good idea on possible classes for our classification.

To enhance our classification and identify the green index or plant cover in the study area, the Normalized Difference Vegetation Index (NDVI) was performed to compliment the earlier unsupervised classification. NDVI is a remote sensing /GIS techniques used over the years by scientists to quantitatively and qualitatively evaluate the vegetation covers of an area (Neelima T.L et al 2013). NDVI as proposed by Rouse, et al (1974) is mathematically defined as:

$$
N D V I=\frac{N I R-R}{N I R+R}
$$

Where, NIR and $R$ are the reflectance in the near infrared and red regions respectively. It is the algebraic combination of red and near infrared bands to represent the amount of green vegetation in the image. In the NDVI, the values for a given pixel value is always in a number that ranges from -1 to +1 . A zero means no vegetation and close to 1 indicates the highest possibility of green leaves (Biehl, 2010).

Field survey/ground truthing of 120 points were conducted on 20-30th July 2016 and was used as our training sites. This were overlaid on unsupervised land cover classes and combined with GeoEye-1 images of 2016 to prepare the supervised classification (Salako et al., 2016). The result of supervised classification produced the following classes of land use land cover in the study area: Forest, Mixed forest, Grassland, Farmland, Adjoining built up and Built up.

\subsection{Land use land covers projection: CA Markov Techniques}

To generate a prediction LULC changes for 2025, the Markovian transition estimator in Idrisi32 was used. 2005 land cover image was input as earlier image while 2015 land cover image was used as later or second image with the number of time periods between the first (earlier image ) and second (later image ) was 10 while the number of time for projection from the second image was also set at 10 years that is 2025. Equal probability was assigned to the entire pixel under estimation. Based on this the following estimation was generated: the probability transition matrix (Table 2), the transition area matrix (Table 3) and conditional probability image. To add the spatial dimension to our prediction the cellular automation (CA) was combined with Markov transition estimation with 2015 land cover image used as basis for projection and the earlier generated transition area matrix. The cellular automation was set at 10 to project for 2025 .

\subsection{Model Validation}

An important stage in the development of any predictive change model is validation. Typically, one gauges one understanding of the process, and the power of the model by using it to predict some period of time when the landcover conditions are known. This is then used as a test for validation. IDRISI supplies a pair of modules to assist in the validation process. The first is called VALIDATE, and provides a comparative analysis on the basis of the Kappa Index of Agreement. Kappa is essentially a statement of proportional accuracy, adjusted for chance agreement. However, unlike the traditional Kappa statistic, VALIDATE breaks the validation down into several components, each with a special form of Kappa or associated statistic based on the work of Pontius (2000): Kappa for no information $=$ Kno . Kappa for location $=$ Klocation $\cdot$ Kappa for quantity $=$ Kquantity $\cdot$ Kappa standard $=$ Kstandard . Value of Perfect 
Information of Location = VPIL $\cdot$ Value of Perfect Information of Quantity = VPIQ With such a breakdown, for example, it is possible to assess the success with which one is able to specify the location of change versus the quantity of change. The accuracy of prediction is measured by the performance of various $\mathrm{K}$ statistics, the higher the value the better the prediction.

\section{RESULT AND DISCUSSION}

\subsection{LULC 2005 - 2015}

In 2005 forest cover (mixed and closed) constituted over $32 \%$ of total LULC with built up covering only 876 ha of land representing $6 \%$ (Fig.3). While, open but adjoining built up constituted about $11 \%$. Five years later, in 2010, part of adjoining built up had changed to cropland thus cropland increased from $19 \%$ in 2005 to $25 \%$ due to Fadama project established at the period (Fig. 4). The Built up was almost at stable point remaining at 5\%. By 2015 the effect of siting KWASU campus in Malete has become obvious, the built up had increased from $5 \%$ in 2010 to $15 \%$ in 2015 covering 2400.03 ha. of land from
803 ha in 2010 (fig.5). Many estate developers and private builders sought for land within KWASU campus and Malete . However forest cover has been worst hit It fell from $17 \%$ in 2005 to about $11 \%$ in 2015 . This was noticeable in Western Bi Ala where about 150 ha of forest land changed to shrubby forest and grassland in 2010 and by 2015 reduced to a narrow strip of forest of less than 45 ha (fig. 5)

Percentage of change analysis between 2005 and 2015 revealed that adjoining lowland and forest cover were the top losers with about $66 \%$ of adjoining lowland lost to either cropland and or built up (Fig. 6). This was followed by forest cover which lost about $34 \%$ of their total land (1500 ha). The top gainer was the built up area which recorded an astronomical increase of $180 \%$ totalling over 1600 hectares of land (Table 2). This was noticeable at the major settlements of Malete, Elemere, and KWASU campus with several residential buildings used either for student hostels or private residences within $500 \mathrm{~m}$ radius of the campus. Smaller settlements like Apodu, Jenkunu and Gbugudu increased by 25\% between 2009 and 2015.

Table.2: LULC change analysis 2005- 2015

\begin{tabular}{lcccccc}
\hline Classes & $\begin{array}{c}\text { Hectares } \\
\mathbf{2 0 0 5}\end{array}$ & $\mathbf{\%}$ & $\begin{array}{c}\text { Hectares } \\
\mathbf{2 0 1 0}\end{array}$ & $\mathbf{\%}$ & $\begin{array}{c}\text { Hectares } \\
\mathbf{2 0 1 5}\end{array}$ & \multirow{\%}{*}{} \\
\hline Open /Built up & 876.42 & 5.5 & 803.25 & 5.2 & 2400.03 & 15.4 \\
Adjoining built up & 1695.96 & 10.9 & 105.57 & 0.7 & 568.17 & 3.7 \\
Cropland & 2986.83 & 19.2 & 3796.74 & 24.6 & 4529.16 & 29.1 \\
Grassland & 4879.71 & 31.4 & 3782.43 & 24.5 & 3210.12 & 20.6 \\
Mixed forest & 2529.09 & 16.3 & 4862.97 & 31.5 & 3142.08 & 20.2 \\
Closed forest & 2591.73 & 16.7 & 2075.22 & 13.5 & 1710.18 & 11 \\
\hline Total & $\mathbf{1 5 5 5 9 . 7 4}$ & $\mathbf{1 0 0}$ & $\mathbf{1 5 4 2 6 . 1 8}$ & $\mathbf{1 0 0}$ & $\mathbf{1 5 5 5 9 . 7 4}$ & $\mathbf{1 0 0}$ \\
\hline
\end{tabular}
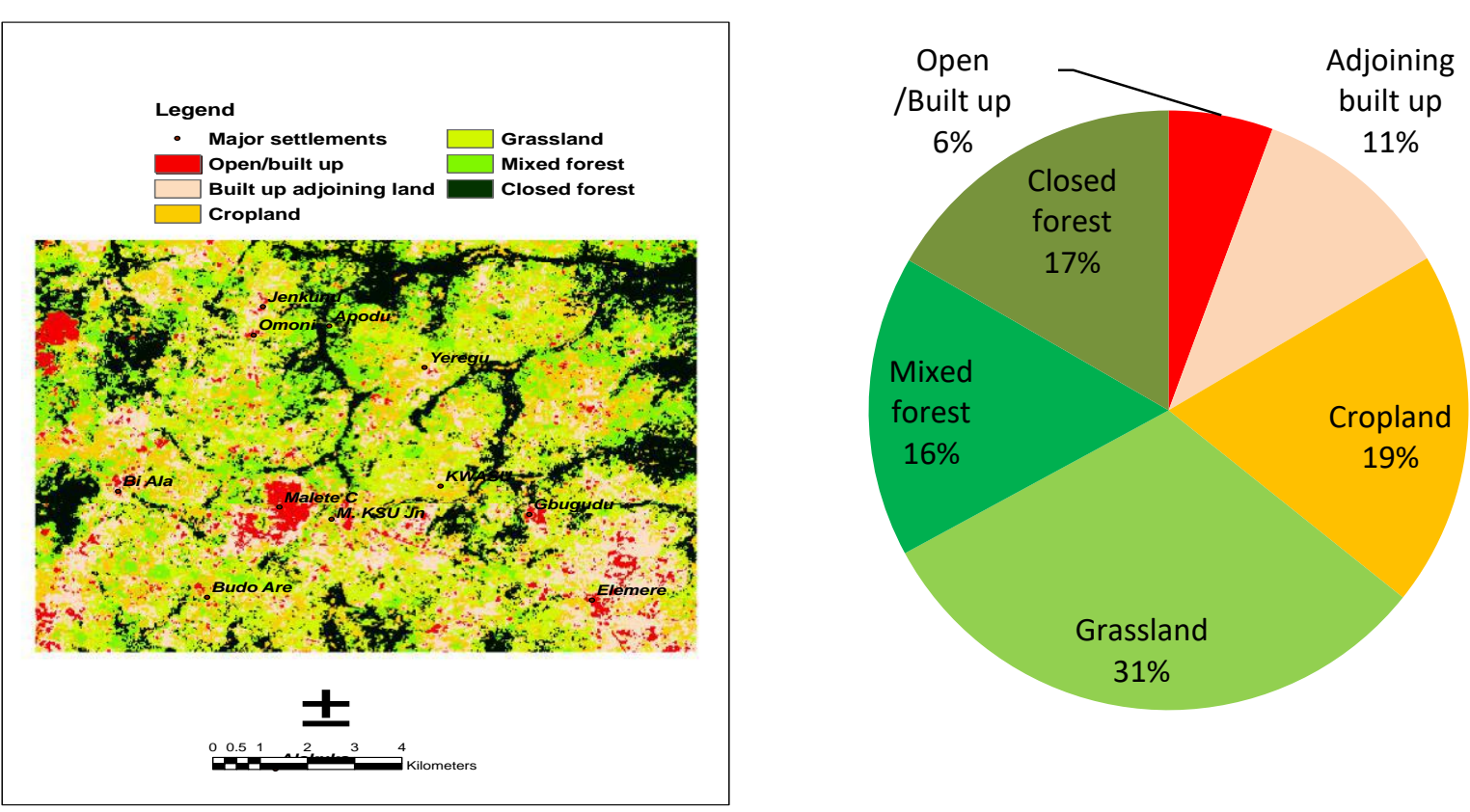

Fig.3: LULC 2005 


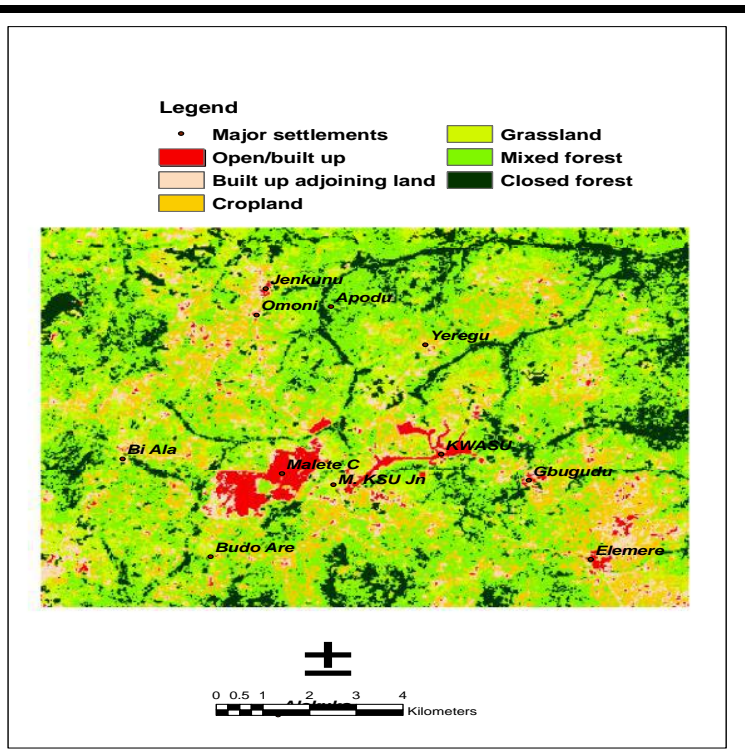

Open

/Built up

$5 \%$

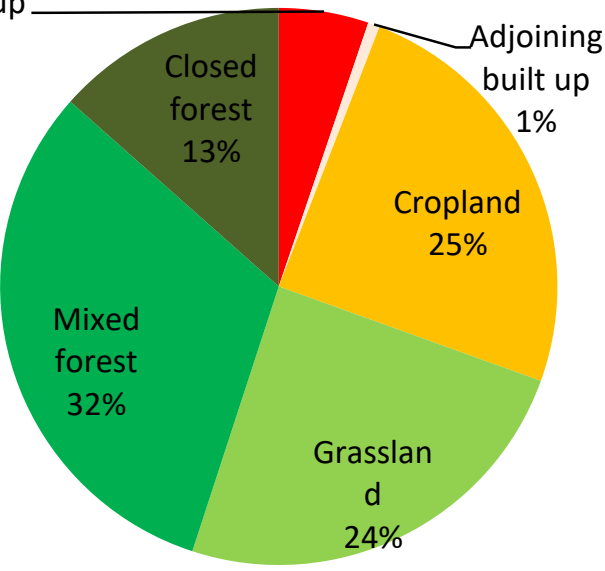

Fig.4: LULC 2010
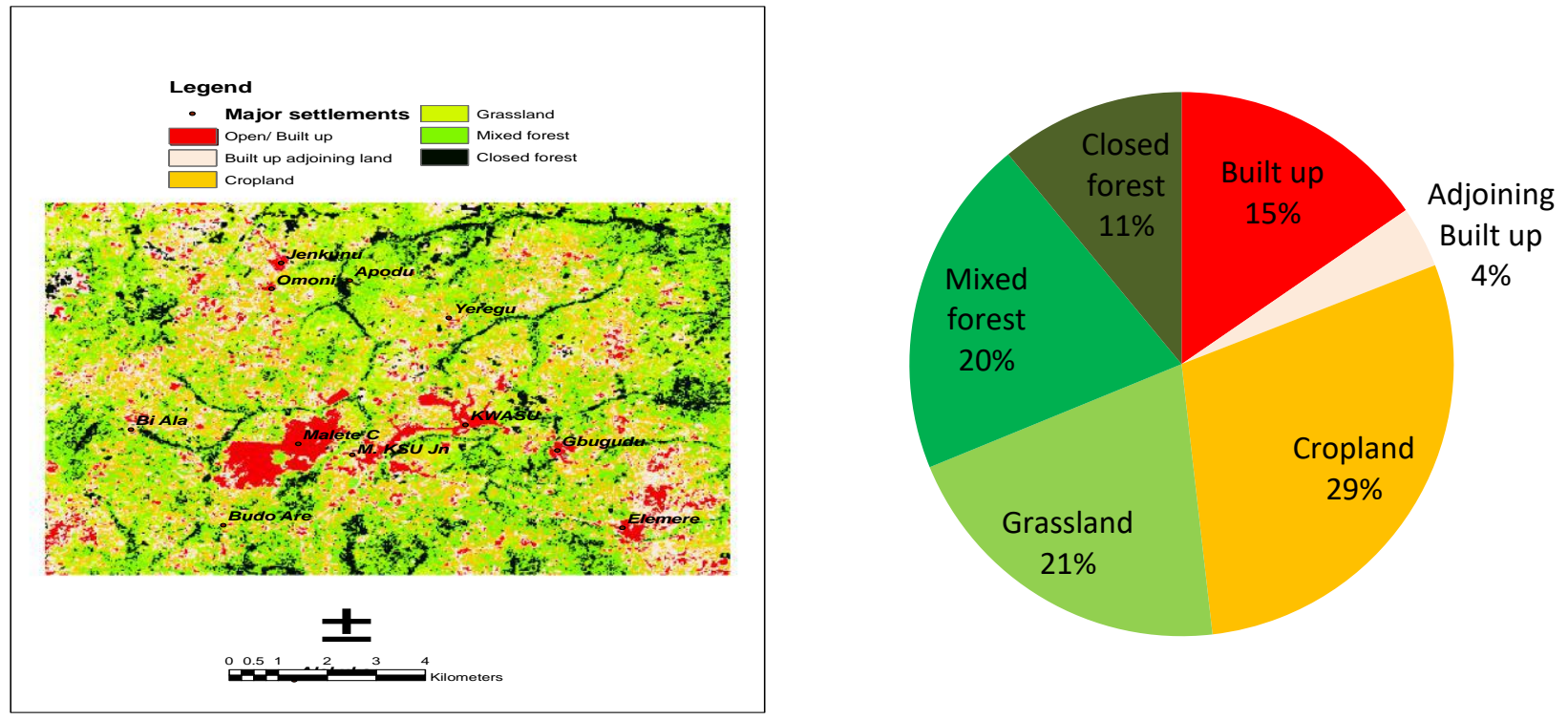

Fig.5: LULC 2015

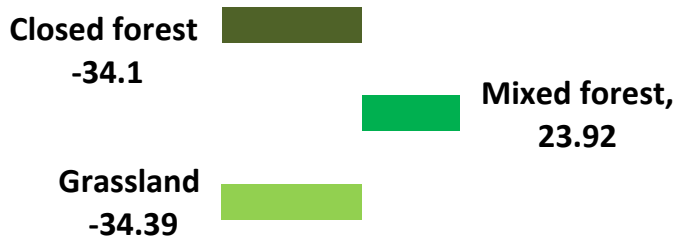

Cropland, $\mathbf{5 1 . 5}$

Adjoining

lowland -66.05

Built up, 180

\begin{tabular}{|c|c|c|c|c|c|c|}
\hline-100 & -50 & 0 & 50 & 100 & 150 & 200 \\
\hline
\end{tabular}

Fig.6: LULC 2005-2015chart 


\subsection{Probability transition matrix for 2025}

Probability matrix of land use land cover change for 2025 was generated using CA Markov model (Table 3). Most land use tend to transit to cropland and Mixed forest especially in Elemere segment, the two LU had the highest transition probability matrix of 0.25 as compared to the overall average of 0.13 The predicted land use changes are as follows: Open adjacent to Built up, Forest to Mixed Forest, Grassland to Cropland.

Table.3: Probability matrix 2015 and 2025

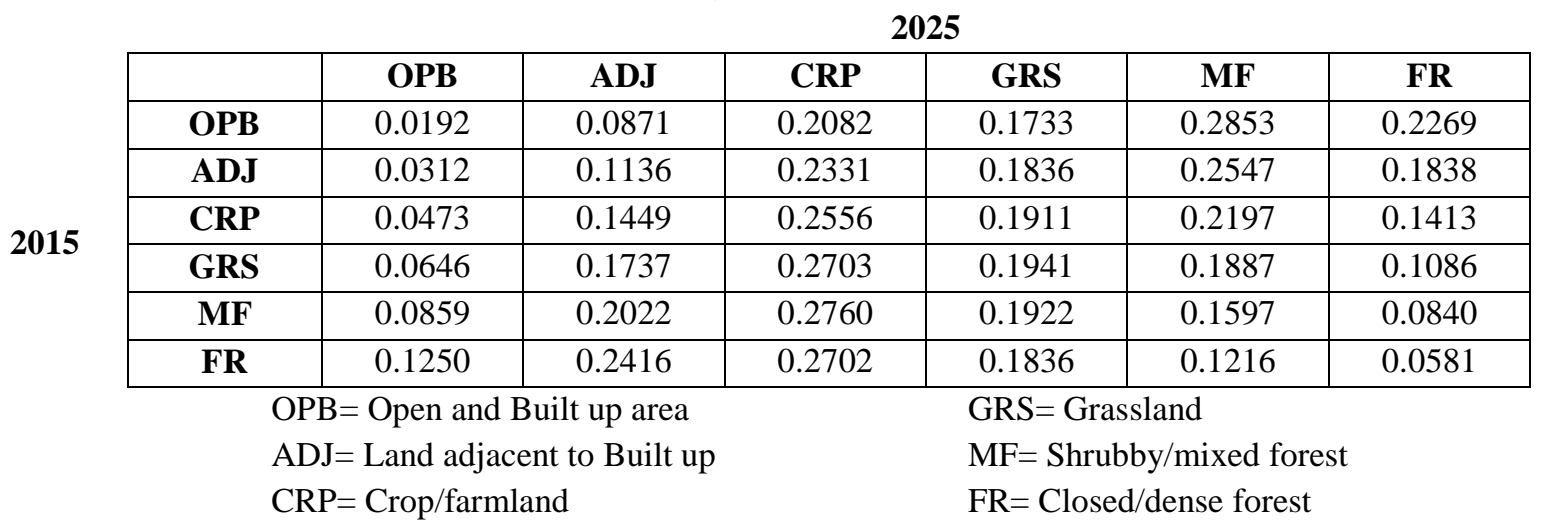

\subsection{Land Use Land Cover Projection 2025}

Land use Land cover change for 2025 was done using CA Markov model. This explains the probability transition matrix and area change calculated from ArcGIS and Multispec. The pattern observed between 2005 and 2015 persisted in the projection with built up predicted to be having the higher percentage gain in land cover land use statistics of about $32 \%$ by closing up the adjoining open land (Fig. 8) while crop land especially around Elemere had a gain of over $4 \%$ Mixed forest equally rose close to $5 \%$ by 2025 and this was probably due to forest degradation which would be losing over $17 \%$ of its 2015 hectares of land (1710.2) to about 1408.14 in 2025 (Table 4).

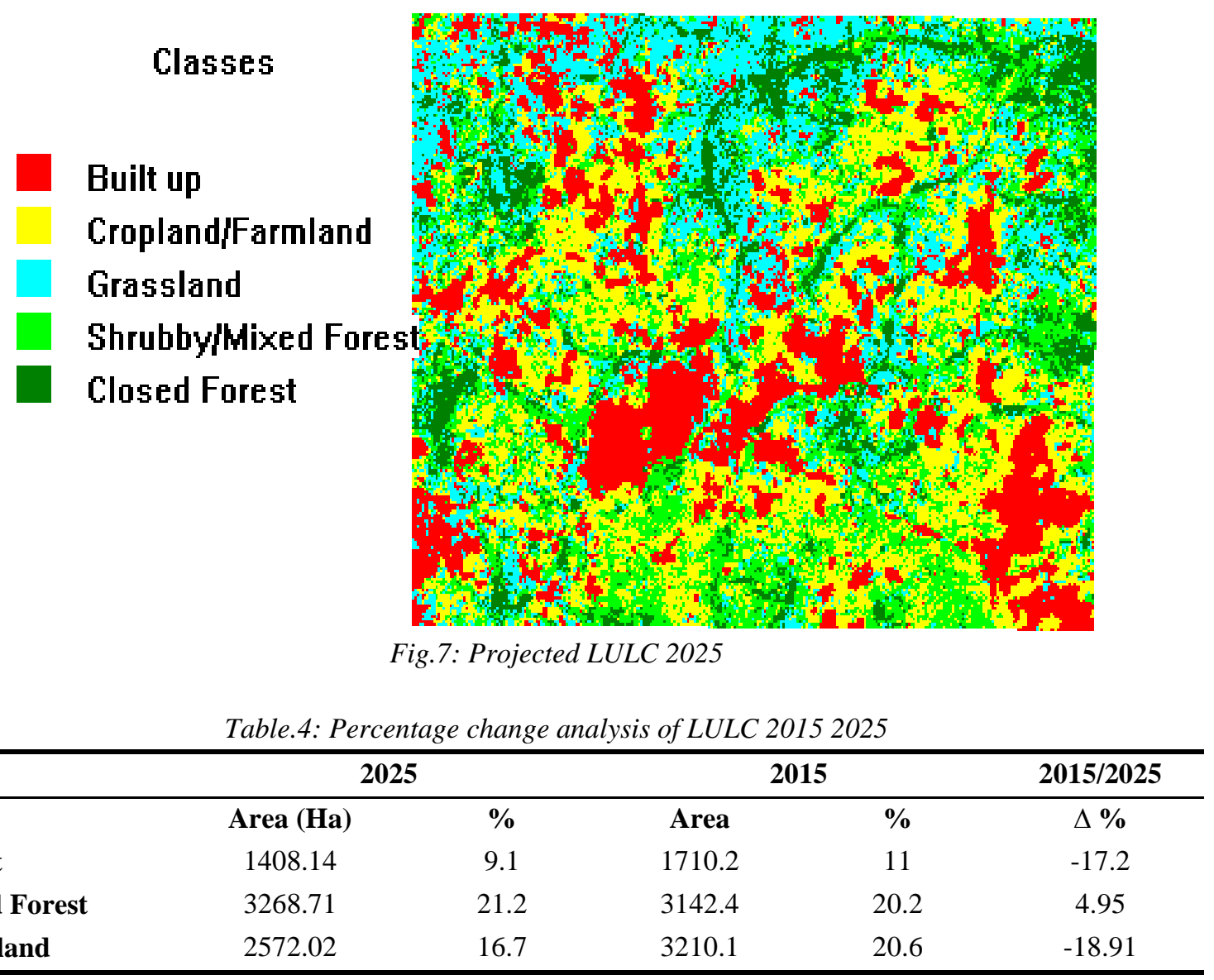




\begin{tabular}{lccccc} 
Crop/Farmland & 4683.63 & 30.4 & 4528.3 & 29.1 & 4.46 \\
Adj Built up & 520.69 & 2.3 & 567.5 & 3.7 & -37.83 \\
Built up & 3066.11 & 20.3 & 2400.1 & 15.4 & 31.82 \\
\hline Total & $\mathbf{1 5 5 1 9 . 3}$ & $\mathbf{1 0 0}$ & $\mathbf{1 5 5 5 8 . 6}$ & $\mathbf{1 0 0}$ & \\
\hline
\end{tabular}

\section{$2015 / 2025 \% \Delta$}

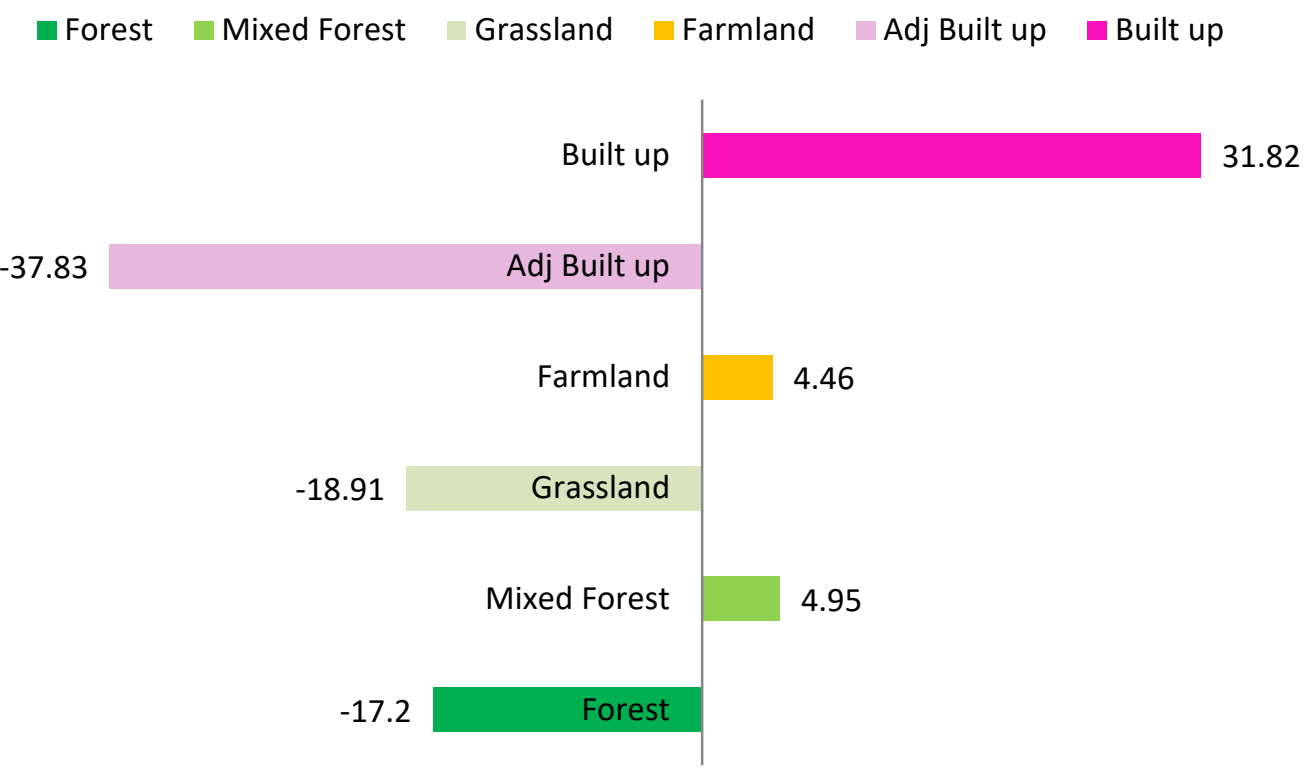

Fig.8: LULC Changes 2015 and 2025

\subsection{Model Evaluation}

For validation of Markov CA model using various Kappa statistics, 2015 observed image was used as referenced and was compared with the simulated image of 2015 to see the similarity between the actual and projected land use land cover map the following Kappa statistics was generated (Table 4). The result shows high performance of the model and its prediction for 2025 and 2030 since most K Statistics (K standatd value of about 0.893 and Klocation of 0.922 Kno -0.8937) were above $80 \%$ (Praveen-Subediet al., 2013).

\section{Table.5: Validation of projected 2015 LULC map with actual 2015 LUC map}

\begin{tabular}{cllll} 
& & \multicolumn{3}{c}{ Ability to Specify Quantity } \\
& & $\mathrm{No}[\mathrm{n}]$ & $\mathrm{Medium}[\mathrm{m}]$ & Perfect[p] \\
Ability to Specify & $\mathrm{Perfect}[\mathrm{P}(\mathrm{x})]$ & $\mathrm{P}(\mathrm{n})=0.9007$ & $\mathrm{P}(\mathrm{m})=0.9754$ & $\mathrm{P}(\mathrm{p})=1.0000$ \\
Location & $\mathrm{Medium}[\mathrm{M}(\mathrm{x})]$ & $\mathrm{M}(\mathrm{n})=0.8461$ & $\mathrm{M}(\mathrm{m})=0.9150$ & $\mathrm{M}(\mathrm{p})=0.9381$ \\
& $\mathrm{No}[\mathrm{N}(\mathrm{x})]$ & $\mathrm{N}(\mathrm{n})=0.2000$ & $\mathrm{~N}(\mathrm{~m})=0.1996$ & $\mathrm{~N}(\mathrm{p})=0.2053$
\end{tabular}

CorrectChance $=0.1996 \quad$ CorrectQuantity $=0.0000 \quad$ CorrectLocation $=0.7154 \quad$ ErrorLocation $=0.0604$ ErrorQuantity $=0.0246 \quad$ PerfectChance $=0.2000 \quad$ PerfectLocation $=0.7947 \quad$ PerfectQuantity $=0.0053 \quad$ VPIL $=$ 0.0604 VPIQ $=0.0231 \quad$ Kno $=0.8937 \quad$ Klocation $=0.9221 \quad$ Kquantity $=0.7488 \quad$ Kstandard $=0.8938$

\section{CONCLUSION AND RECOMMENDATION}

- The adjoining built up will be closed up and fully merged with the built up area for developmental project by 2030 .

- Malete-Elemere growth pole axis is at risk of chaotic urban growth if action is not taken now.
- BialaBudo Are forest will be lost and transit to shrubby forest and perhaps grassland thus deplete the area of high biodiversity values.

- The North East section is potentially forest reserve zone and could be designated as conservation area. 
- Sustainable land use plan should give high priority to enhancement of community/land biodiversity value.

- Full community participation and input in land use planning.

- High level of adaptability in response to change with emphasis on bottom top approach to planning.
- Planning based on up-to-date data and full integration of geospatial data.

- Functional government agency to regulate, administer and implement plan policy e.g. Malete Elemere Development Area Commission.

Recommendation: Three zones of different land use planning are recommended

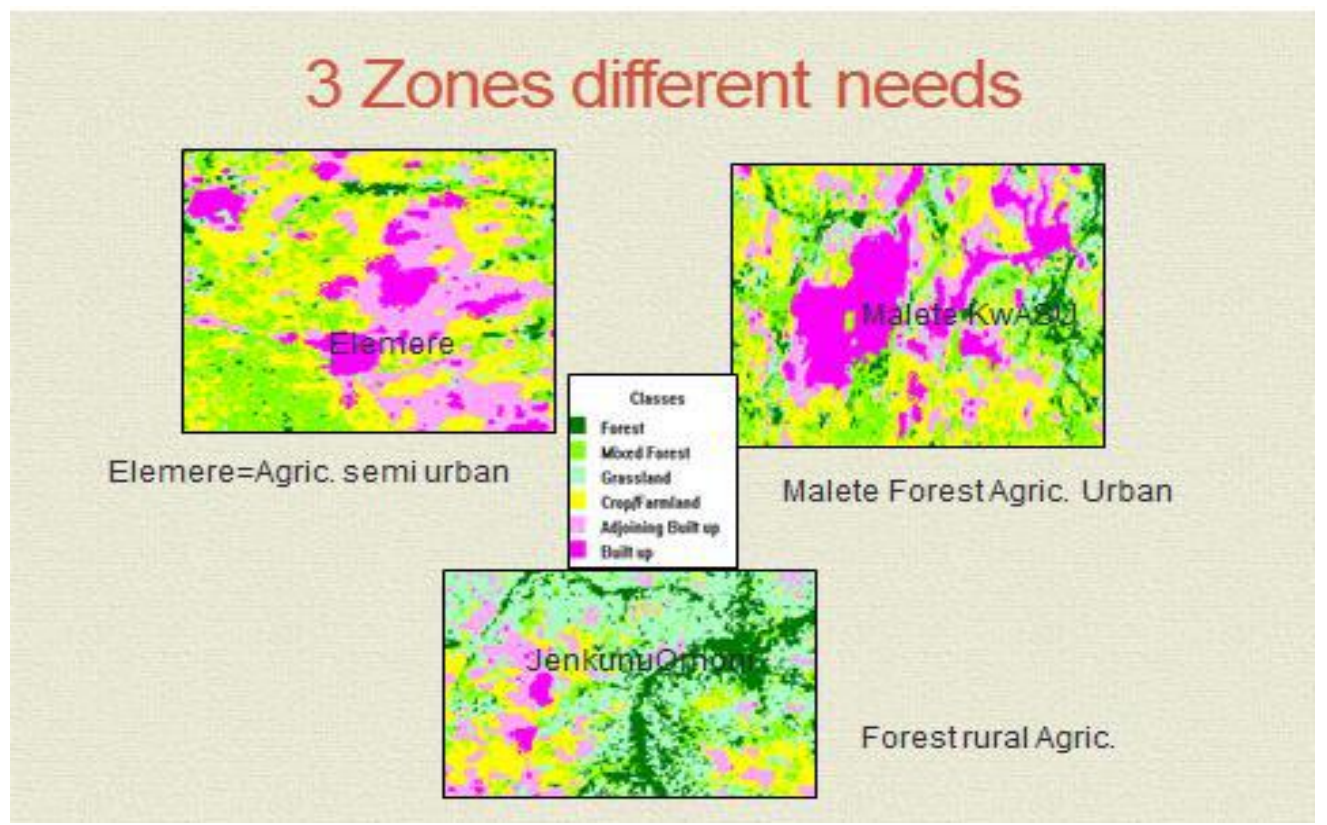

\section{REFERENCES}

[1] Barthlott, W., Kier, G. \& J. Mutke (1999, in press): Biodiversity - The Uneven Distribution of a Treasure. - In: NNA Reports, Vol. 12, Special Issue 2. Forests in Focus: Proceedings 'Biodiversity Treasures in the World's Forests', 3-7 July 1998. (ISSN 0935 - 14 50. )

[2] Biehl, L. (2010) Multi spec Tutorialshttp://dynamo.ecn.purdue.edu/ biehl/Multi Spec/.

[3] Bohman, C.D, Mergen, D.E, Montoya, S (2004) Plant Cover Estimation: A contiguous Daubenmire frame.

[4] Boles S.H, Xiao X, Liu B J, Zhang Q Munkhtuya S C, Chen S, Ojima, and D (2013) 'Land cover Characterization of Temperate East Asia using multi-temporal vegetation sensor Data' Remote Sensing of Environment 90 (2004) 477-489

[5] Biodiversity Resources Centre (2013) The habitat (biodiversity) mapping project for over ten towns in Hudsonia New York.

[6] Brohman, R., and L. Bryant, editors.(2005). Existing vegetation classification and mapping technical guide.GTR WO-67, USDA Forest Service,
Ecosystem Management Coordination Staff, Washington, DC, USA.

[7] Ceccato, P., Flasse, S., \&Gregoire, J. -M. (2002a). Designing a spectral index to estimate Vegetation water content from remote sensing data: Part 2.Validation and applications'.Remote Sensing of Environment, 82, 198-207.

[8] Chebet (2013) 'An Assessment of Land Use and Land Cover in and Around Kakamega Forest in Kenya Using GIS and Remote Sensing', Journal of Emerging Trends in Engineering and Applied Sciences (JETEAS) 4(1): 46-53 () Scholarlink Research Institute Journals, 2013 (ISSN: 2141-7016) jeteas.scholarlinkresearch.org

[9] Defries, R., \& Townshend, J. (1994). 'NDVIderived land classifications at a global scale'. International Journal of Remote Sensing, 17, 35673586.

[10]Foody, G.M. (2002) Status of Land Cover Classification Accuracy Assessment.Remote Sensing Environment. 80: 185-201.

[11] Ghorbani A, Mossivand A.M and Ouri A.E (2012) 'Utility of the Normalized Difference Vegetation Index (NDVI) for land/canopy cover mapping in 
Khalkhal County (Iran)', Annals of Biological

Research, 2012, $3 \quad$ (12):5494-5503

(http://scholarsresearchlibrary.com/archive.html)

ISSN 0976-1233

[12] Gillison, A.N. and AndersonDJ.(1981). Vegetation classification in Australia. Commonwealth Scientific and Industrial Research Organization: Canberra, Australia.

[13] Gladstone, W. and F. Thomas Ledig (1990)."Reducing pressure on natural forests through high-yield forestry."Forest Ecology and Management 35(1): 69-78.

[14] Global Bioversity Information Facility (GBIF) http://www.gbif.org

[15] Hegazy I R and Kaloop M R (2015) Monitoring urban growth and Land Use change detection with GIS and rmote sensing echniques in Daqhalia governorate Egypt. International Journal of Sustainable Built Environment 2212-6090

[16] Lowry, J. H, Jr., R. D. Ramsey, K. Boykin, D. Bradford, P. Comer, S. Falzarano, W. Kepner, J.Kirby, L.Langs, J. Prior-Magee, G. Manis, L. O'Brien, T. Sajwaj, K. A. Thomas, W. Reith, S. Schrader, D. Schrupp, K. Schulz, B. Thompson, C. Velasquez, Wallace, E. Waller and B. Wolk.(2005). Southwest Regional Gap Analysis Project: Final Report on Land Cover Mapping Methods, RS/GIS Laboratory, Utah State University, Logan, Utah.

[17] Lu, D. and Q. Weng (2007). A survey of image classification methods and techniques for improving classification performance. International Journal of Remote Sensing, Vol.28(5): 823-870.

[18] Mutke, J. \& W. Barthlott (1999, in press): Some aspects of North American phytodiversity and its biogeographic relationships. - In: S.-W. Breckle, B. Schweizer\& U. Arndt (eds.): Results of worldwide ecological studies - Proceedings of the $1^{\text {st }}$ Symposium by the A.F.W. Schimper-Foundation from H. and E. Walter - Hohenheim, October 1998. Verlag Günter Heimbach, Stuttgart.

[19] Pontius Jr, R.G., 2000. Quantification error versus location error in comparison of categorical maps.Photogrammetric Engineering and Remote Sensing. 66(8) pp. 1011-1016.

[20] Praveen Subedi ,KabirajSubedi and BinaThapa (2013) Application of a hybrid Cellular automationmarkov (CA- markov) MOdel in Land use Change prediction: a case study of Saddle Creek Drainage basin Florida Applied Ecology and Environmental Sciences pp.126-132

[21] Trisurat, Y., A. Eiumnoh, S. Murai, M.Z. Husain and R.P. Shrestha. (2000). Improvements of tropical vegetation mapping using a remote sensing technique: a case study of Khao National Park, Thailand. International Journal of Remote Sensing, 21: 2031-2042.

[22] USGS/Gap (2002) Southwest Regional Gap analysis project (SWReGAP) 2002 mapping land cover Large Geographic Areas. Integration of GlS and Remote sensing technologies

[23] Yang, X. and. Lo, C.P (2002).Using a Time Series of Satellite Imagery to Detect Land Use andLand Cover Changes in the Atlanta, Georgia Metropolitan Area.International Journal of RemoteSensing. Vol 23, No. 9, 1775-1798.

[24] Yuan, F., Sawaya, K.E., Loeffelholz, B.C., and M.E.Bauer (2005).Land Cover Classification and Change Analysis of the Twin Cities (Minnesota) Metropolitan Area by multitemporal Landsat Remote Sensing.Remote Sensing of Environment. 98: 317-32

[25] Xiao, X., Braswell, B., Zhang, Q., Boles, S., Frolking, S., \& Moore, B (2003). Sensitivity of vegetation indices to atmospheric aerosols: Continental-scale observations in Northern Asia. Remote Sensing of Environment, 84, 385-392 